\section{ASPECT IN EAST AND MAINLAND SOUTHEAST ASIAN LANGUAGES - A FIRST STEP}

\section{Walter Bisang ${ }^{1}$}

\begin{abstract}
The present paper has two intentions. It wants to sketch a typological basis for describing aspect in individual languages and for cross-linguistic comparison and it wants to present some first ideas of how aspect works in languages of East and mainland Southeast Asia. Aspect will be defined in terms of a "selection theory of aspect". Thus, aspect markers are understood as operators that select matching temporal phases provided by the temporal boundaries as they are determined (a) in the lexicon of verbs or (b) in additional, overt structures such as resultative verbs, markers of Aktionsart, quantified noun phrases and adverbials. Markers of perfective aspect highlight temporal boundaries, while imperfective markers present a state of affairs without reference to them. Languages of East and mainland Southeast Asia differ from prototypical aspect languages such as Russian, Bulgarian or Greek inasmuch as aspect marking is not obligatory and inasmuch as there is no binary opposition of perfective vs. imperfective. In spite of this, there are markers that interact with temporal boundaries and that show typologically remarkable properties not
\end{abstract}

${ }^{1}$ Ph.D., Professor, Institut für Allgemeine und Vergleichende Sprachwissenschaft Johannes Gutenberg-Universität Mainz, Mainz, Germany described for other languages. East and mainland Southeast Asian languages may thus contribute a number of new perspectives on the aspect properties.

\section{General outline of the paper}

Aspect and its definition is a notorious problem in linguistics. Few fields have been treated and still are treated more extensively and with more terminological and notional confusion than the one of aspect. The aim of the present paper within this rather complex situation is to provide a coherent definition of aspect which can be used for cross-linguistic comparison and which is able to reveal the special properties of East and mainland Southeast Asian languages. For that purpose, section 2 deals with different conceptualizations of aspect, the definition of aspect adopted in this paper and the working of such a system illustrated by some data from Modern Greek. Section 3 will try to show that East and Southeast Asian languages differ from aspectual languages of Europe such as Greek (both Ancient and Modern), Russian or Bulgarian inasmuch as there is no obligatory selection from a binary pair of perfective vs. imperfective meaning ( $\$ 3.1$ ). In spite of this, the semantics of a number of markers in East and mainland Southeast Asian languages can be described in terms of reference to temporal boundaries. Thus, they belong to the domain of aspect even though the details concerning their semantics deviate considerably from the way in which European aspectual markers interact with temporal boundaries. This will be illustrated by two examples, one from Modern Standard Chinese ( $\S 3.2$ ), one from Thai ( $\$ 3.3$ ). In addition, a method of how to distinguish aspectual categories in East and mainland 
Southeast Asian languages will be sketched (cf. § 3.3 again). The paper ends with a short conclusion in section 4 .

\section{Conceptualizations of aspect and its working in Modern Greek}

Given the plethora of conceptualizations of aspect, it is necessary to clarify how aspect is understood at the beginning of this paper to provide a theoretical background from which the problem of dealing with aspect and its expression in East and mainland Southeast Asian can be described more coherently. Since Sasse (2002) recently published an excellent guide through the terminological and conceptual thicket of approaches to aspect, I shall follow his historical and conceptual assessment of this phenomenon in the first subsection (cf. \& 2.1). In the second subsection ( $§ 2.2$ ), I shall briefly look at Modern Greek to illustrate how a language with an obligatory aspect system works.

\subsection{Conceptualizations of aspect}

One tradition dealing with aspect called "the viewpoint approach" by Sasse (2002: $208-211)$ is based on the semantics of the inflectional aspect categories as represented by "aspectual pairs" in Slavonic languages (e.g. Koschmieder 1928/1929, 1934), aorist vs. imperfective in Greek (Ancient and Modern) or passé simple vs. imparfait in French. For this tradition, there is a holistic semantic opposition reflected by the above morphological pairs. In some more recent publications, this opposition has been described in terms of totality or in terms of boundedness (to mention just two opposition pairs). Thus, the perfective either refers to a state of affairs as a whole while the imperfective does not (Comrie 1976), or the perfective refers to the temporal boundaries of a state of affairs while the imperfective disregards them (Maslov 1962; Dahl 1985 against Comrie 1976). While aspect is a fully inflectional category which is obligatory in languages such as Russian, Bulgarian or Greek, there is another category called "Aktionsart" which is derivational. Aspect is defined as a grammatical category which does not change the basic meaning of a verb. In contrast, Aktionsart is taken as a device of word-formation which does not belong to the scope of grammar. Typical functions expressed by Aktionsart are inchoative (a state of affairs is characterized by its initial temporal boundary), terminative (the final point of a state of affairs is marked), punctual (the beginning and the end of a state of affairs coincide), resultative (a state of affairs reaches a certain state), iterative (a state of affairs takes place several times) and durative (a state of affairs lasts for a certain time span).

While the "viewpoint approach" has its historical roots in the European continent, another approach called "time-schema approach" by Sasse (2002: 213 - 216) established the AngloAmerican tradition. The aim of this approach is to set up classes of states of affairs "according to a logical concept of temporal constitution, which defines the different inherent temporal characteristics of states, events, processes, etc." (Sasse 2002: 214). The most prominent publications from this tradition are Vendler (1967) and later Dowty (1979). Vendler introduced the four categories of states, activities, accomplishments and achievements. These classes can be defined by the features [ \pm static], $[ \pm$ telic] and $[ \pm$ 
punctual]. Verbs with the property of [+static] are non-dynamic, i.e., no change can be observed at any time in which a static state of affairs is true. Verbs with the feature [+telic] have an inherent terminal point. Finally, verbs with the feature of [+punctual] denote state of affairs with no internal duration. The following table shows how these three features together define the four classes of verbs defined by Vendler (1967):
State

Activity

Accomplishment

Achievement [+static],[-telic], [-punctual] [-static], [-telic], [-punctual] [-static], [+telic], [-punctual] [-static], [+telic], [+punctual] be sick, be dead, love, know march, walk, swim, read melt, freeze, learn pop, explode, collapse, shatter

Table 1: Vendler's (1967) classes of verbs defined by the features [ \pm static $],[ \pm$ telic $],[ \pm$ punctual $]$.

Van Valin \& LaPola (1997) provide a good survey of tests which help to find out to what class a given verb in a given language belongs. The following table is a summary of these tests (first column) and the results they yield if they are applied to Vendler's (1967) four classes (,no, means "the test does not work", yes, means "it works", the asterix , , means that there are some further restrictions):

\begin{tabular}{|c|c|c|c|c|}
\hline Criterion & States & $\begin{array}{l}\text { Achieve- } \\
\text { ments }\end{array}$ & $\begin{array}{l}\text { Accomplish- } \\
\text { ments }\end{array}$ & Activities \\
\hline Occurs with progressive & No & No & Yes & Yes \\
\hline $\begin{array}{l}\text { Occurs with adverbs } \\
\text { like vigorously, actively, etc. }\end{array}$ & No & No & No & Yes \\
\hline $\begin{array}{l}\text { Occurs with adverbs } \\
\text { like quickly, slowly, etc. }\end{array}$ & No & No* & Yes & Yes \\
\hline $\begin{array}{l}\text { Occurs with } X \text { for an hour, } \\
\text { spend an hour Xing }\end{array}$ & Yes* & No & Irrelevant & Yes \\
\hline Occurs with $X$ in an hour & No & No* & Yes & No \\
\hline
\end{tabular}

Table 2 Van Valin \& LaPolla's Criterion for Classifying the Four Aspectual Verbs 
In principle, there is nothing to say against such an approach. The problem is in what way this definition helps understanding languages which are prototypically described in terms of aspect, i.e., languages such as Russian, Bulgarian or Greek:

There is nothing ipso facto wrong with allowing the term "aspect" the widest possible scope; the problem comes when we try to understand what it is that the speaker of a language with aspectual opposition knows which a nonspeaker does not know, and con-sider how to model this knowledge in the grammar.

(Binnick 1991:209)

In the light of this problem, I follow an approach called "selection theory of aspect" by Bickel (1997, also cf. Sasse 2002: $222-225$ ). Theories of this type integrate the time-schema approach and the viewpoint approach in the sense that there is an opposition pair of two operators, perfective and imperfective, that select matching temporal phases provided by the semantics of a given state of affairs. The first part of this theory covers the fact that languages such as Russian, Bulgarian or Greek have an obligatory morphological opposition pair and thus reflects the viewpoint approach, or ASPECT1 in Sasse's (2002) more general terms. The second part can be compared to the time-schema approach in principle, although individual selection theories use specific temporal features. If one adopts Sasse's more general term of ASPECT2 for theories based on the temporal constituency of state of affairs, one can say that ASPECT1 representing the two operators of perfective vs. imperfective interacts with ASPECT2 representing features concerning the tempo-ral structure of a state of affairs.

Vendler's (1967) system of verb classes represents one type of ASPECT2 with which the perfective and the imperfective operators from ASPECT1 can interact. Another approach to ASPECT2 developed by Breu (1985) and Sasse (1991), which I shall prefer in this paper for 4 reasons to be presented below, is based on the two components necessary for representing the temporal structure of states of affairs, i.e., the situation boundary and the phase boundary between the situation boundaries. An even more elaborate version of this approach was recently presented by Breu (2000). Since what matters for the present study is a verb class characterized by an initial temporal boundary (cf. $\S 3.2$ ), a verb class neglected in Vendler's 1967 classification, Sasse's (1991) approach is sufficient for the purpose of this paper. $\mathrm{He}$ distinguishes five classes of states of affairs (cf. table 3 below) which are based on the following components: the initial change of situation (CS1), the situation (S) itself and the terminal change of situation (CS2).

$\begin{array}{lll}\text { Totally stative (TSTA): } & \text { CS1 [S] CS2 } & \text { know, be sitting, exist } \\ \text { Inceptive-stative (ISTA): } & \text { [CS1 S] CS2 } & \text { sit down, get to know } \\ \text { Action (ACTI): } & \text { [CS1 S CS2] } & \text { work, sing, drink } \\ \text { Gradually terminative (GTER): } & \text { CS1 [S CS2] } & \text { die, kill, melt } \\ \text { Totally terminative (TTER): } & \text { CS1 S [CS2] } & \text { reach }\end{array}$

Table 3: Sasse's (1991) five classes of states of affairs 
These classes can be more easily characterized by the symbol $\tau$ for the situation boundary or transition and the symbol of $\varphi$ for the phase as introduced by Bickel (1997). This model y ields states of affairs with the structure of $[\tau \varphi \tau]$ with a phase and its initial and its terminal temporal boundary (cf. action/ ACTI), structures with the phase plus an initial $[\tau \varphi]$ (inceptive/stative/ISTA) or a terminal $[\varphi \tau]$ (gradually terminative/ GTER) boundary or still other structures consisting only of a transition $[\tau]$ (totally terminative/TTER) or a phase $[\varphi]$ (totally stative/TSTA).

The Breu/Sasse system does not only differ from the Vendler/Dowty system with regard to the existence of a verb class characterized by an initial temporal boundary, it also differs with regard to its scope. While the Vendler/Dowty system exclusively looks at the lexical prop :rties of individual verbs, the Breu/ Sass system has to be understood in terms of state of affairs as a whole, consisting of the verb with its temporal semantics plus the contributions of its arguments and its adjuncts.

In selection theories, the markers of ASPECT1 (perfective vs. imperfective) directly operate on the temporal structure of ASPECT2 in the following way:

The marker of $\mathrm{i}$ mperfective aspect presents a state of affair as a situation without any reference to its temporal boundaries. It highlights the phase.

The marker of perfective aspect presents a state of affairs as a change of state with explicit reference to its inherent temporal boundaries.
From the perspective of a selectional theory of aspect, a language has aspect if there is an obligatory expression of ASPECT1, i.e., if there is an obligatory marking system distinguishing perfective vs. imperfective which interacts with the temporal structure of a verb or a state of affairs (ASPECT2).

\subsection{A sketch of the Modern Greek aspect system}

A brief look at Modern Greek is to illustrate the interaction of the temporal structure of state of affairs with the aspectual opposition pair of perfective vs. imperfective. Modern Greek is a language with an obligatory perfective vs. imperfective distinction. The distinction between these two categories is expressed by two different verbal stems, a perfective and an imperfective stem, plus two partly different sets of person-agreement suffixes. In the case of the verb 'to write' the two stems are graf-, write [imperfective]' vs. graps'write [perfective]'. The person suffixes for the active forms of the perfective (called "aorist" in traditional G reek grammar) and of one conjugation class of the imperfective (called "imperfect" in Greek grammar) are: $-a$ (1sg), -es $(2 \mathrm{sg}),-e(3 \mathrm{sg}),-$ ame $(1 \mathrm{pl}),-$ ate $(2 \mathrm{pl})$ and $-a n(e)(3 \mathrm{pl})$. In a ddition, the active imperfective suffixes of a second conjugation class are: -usa (1sg), -uses (2sg), -use (3sg), -usame (1pl), -usate $(2 \mathrm{pl})$ and - usan(e) (3pl). F inally, the perfective (aorist) and the imperfective (imperfect) of many verbs are characterized by an invariable prefix $e$ . Thus, the two forms of the verb 'to write' in the first person singular are $e$ graf-a 'I wrote [imperfective/ imperfect]' vs. e-graps-a 'I wrote [perfec-tive/aorist]'. If the person suffixes vary according to conjugation 
class, the difference between perfective and imperfective cannot only be seen from differences in the stem but also from differences in the person suffixes. This is the case with the verb 'to love': a Vap-úsa 'Il loved [imperfective]' vs. $a$ Vapis-a 'Ifell in love [perfective]'. From these two examples one can see that the morphological system of Modern Greek provides two different forms for each verb, one for perfective, the other for im-perfective. In addition to the above regular patterns, there are many irregularities which will not be treated here although they also maintain the perfective/imperfective distinction in the vast majority of cases.

The possibility to use the two forms corresponding to perfective vs. imperfective and the differences of meaning depends on the semantic class to which the verb belongs. As can be seen from Table 4 below, based on the five semantic classes distinguished in the Sasse/Breu model (cf. Table 3 above), totally stative verbs (TSTA) can only occur with the imperfective form because there simply is no temporal boundary to be highlighted by the perfective. With inceptive-stative verbs, the perfective form applied to the initial boundary yields an inceptive interpretation 'start to ...', while the imperfective form does not imply this component of meaning because it does not refer to temporal boundaries, it only refers to the state expressed by the situation (statal). In the case of action verbs (ACTI), the perfective points out that the state of affairs expressed by the verb is viewed from within its initial and terminal boundaries (delimitative) whereas the imperfective focuses on the state of affairs in progress (progressive) and disregards the temporal boundaries. In the case of gradually terminative verbs (GTER), the perfective aspect highlights the result of the state of affairs as represented by the terminal boundary (resultative), whereas the imperfective concentrates on the situation before that boundary (prestadial). Finally, totally terminative verbs (TTER) can only take the perfective aspect.

1. TSTA: These verbs only occur with the imperfective:

$$
\text { éxo 'have', kséro 'know', lípo 'lack', etc. }
$$

\section{ISTA:}

IMP: $\quad a$ Vap-úsa 'I loved'

PFV: $\quad a$ Vapis- $a$ 'I fell in love'

Vnóriz-a 'I knew' (statal)
Vnóris-a 'I got to know' (inceptive)

3. ACTI:

IMP: Dúlev-a

'I was working' (progressive)

PVF: Dúleps-a

'(and then) he worked (and) ...' (delimitative)

4. GTER:

IMP: péQen-a 'I was dying'

ar V-úsa 'I was expected for some time' (prestadial)

PVF: péQan-a 'I died' ár Vis-a 'I was late' (resultative)

5. TTER: Only the perfective aspect can be applied to these verbs.

Table 4: The use of Modern Greek perfective vs. imperfective (adapted from Sasse 1991) 
There are some contexts in which clearly only one aspect can be selected. Such contexts can be used for testing whether a language has an aspect system. One such context is called the schema of incidence (German: Inzidenzschema; cf. Pollak 1988 [1960] ultimately going back to Koschmieder 1934), in which one state of affairs (A) is going on while suddenly another states of affairs (B) comes in. In such a situation illustrated by example (1), state of affairs ( $A=$,to be silent') must be expressed by the imperfective, while state of affairs ( $\mathrm{B}=$, a cannon-shot was heard') must take the perfective:

$$
\begin{aligned}
& \text { oli sopen-an, otan } \\
& \text { all be.silent-IMP:3.PL when } \\
& \text { exafna } \\
& \text { suddenly } \\
& \text { akus-tik-e enaspirovolismos } \\
& \text { hear-PASS-PFV:3.SG one } \\
& \text { cannon-shot }
\end{aligned}
$$

All of them] were silent when all of a sudaen a cannon-shot was heard.

It is needless to say that a test like the schema of incidence only works in languages in which the marking of perfective vs. imperfective is obligatory (also cf. 3.1).

\section{Aspect in East and mainland Southeast Asian languages}

This section starts with a description of indeterminateness as a basic typological property of East and mainland Southeast Asian languages ( $\$ 3.1$ ). Because of this property, the languages of this area systematically undermine a number of tests which work for European languages. Nevertheless, it is possible to compare the semantics of aspectual markers in European lan-guages and in
East and mainland Southeast Asian languages. As closer semantic analyses of the marker -le in Modern Standard Chinese (§ 3.2) and the marker lé $w \mathrm{w}$ in Thai $(\S 3.3)$ reveal, the way in which these markers operate on temporal boundaries considerably differs from the semantics known for European languages. The lack of an obligatory aspect system also calls for a method of analysis which is adapted to the typological properties of East and mainland Southeast Asian languages. Subsection 3.3 tries to sketch such a method.

\subsection{Indeterminateness in East and mainland Southeast Asian languages}

As I tried to show in several publications (cf. e.g. Bisang 1996, 2001) there are no obligatory grammatical categories in East and mainland Southeast Asian languages. Probably the best known instance of indeterminateness is the lack of obligatory arguments (pro drop). But there are also a lot of other categories such as number, tense and aspect (with verbs) or number and reference (with nouns) which can be omitted in East and mainland Southeast Asian languages. Thus, the following two informa-tionally rather indetermined utterances in Thai are perfectly acceptable in a context in which no particular information beyond the concept denoted by the verb (2) or the noun ( 3 ) is needed:
(2)
(khăw) maa. he come
(He) comes/has come/is coming/will come/etc.




\author{
khăw síi sàpparót. \\ he buy pineapple \\ He bought a pineapple/ \\ pineapples/ the pineapple/ the \\ pineapples.
}

In my definition of obligatority, I follow C. Lehmann's (1995) paradigm-based ap-proach discussed under the term of transparadigmatic variability:

By this [i.e. transparadigmatic variability; W.B.] we mean the freedom of the language user with regard to the paradigm as a whole. The paradigm represents a certain category, and its members, the subcategories (or values) of that category. There may then be a certain freedom in either specifying the category by using one of its subcategories, or leaving the whole category unspecified. To the extent that the latter option becomes constrained and finally impossible, the category becomes obligatory. We shall therefore use the term 'obligatoriness' as a more handy - converse equivalent of 'trans-paradigmatic variability'.

(C. Lehmann 1995: 139)

Thus, a category represented by a paradigm is obligatory if the speaker is forced to specify a certain value or subcategory of that paradigm. Conversely, indeterminateness means that the speaker only needs to mention a subcategory $\mathrm{X}$ of a particular category if $s$ he assumes that it is not activated (cf. Lambrecht 1994) in the hearer. In this case, it is not possible to infer from the speaker's not mentioning $X$ that not$X$ is meant (cf. Bybee 1997: 34).

Since the speaker is not forced in East and mainland Southeast Asian languages such as Thai or Chinese to express a subcategory of aspect (perfective vs. imperfective), these languages are certainly indeterminate with regard to aspect. As a consequence, they do not have an aspect system comparable to Greek, Russian or Bulgarian. None of the obligatority-based tests such as the schema of incidence (cf. $\S 2.2$, example (1)) work with East and mainland Southeast Asian languages, since the speaker is not bound to use an aspect marker. Nevertheless, this does not mean that these languages cannot have markers whose semantics clearly are aspectual, even though the details of these semantics differ remarkably from the more familiar systems in aspectual languages of Europe. This will be illustrated by looking at the marker -le of Modern Standard Chinese in subsection 3.2. Subsection 3.3 will present a short methodological sketch of how to describe aspect in Thai followed by another semantically remarkable case concerning the marker lécw.

\subsection{On aspect in Modern Standard Chinese}

The system of ASPECT2 adopted in this paper is the one by Breu/Sasse(cf. above). The reason for this is that this system pays due attention to both temporal boundaries, the terminal as well as the initial boundaries, while the Vendler/Dowty system only integrates the terminal boundary. As will be seen in the rest of this subsection, it is possible for a marker to operate only on the terminal boundary, a fact which remains unreveiled from the perspective of the Vendler/Dowty system because this system precludes a look at initial boundaries. The marker to be analyzed in some detail is Modern Standard Chinese -le (also cf. Bisang, forth). As is illustrated by (4), the marker le can 
occur in two positions in Modern Standard Chinese:

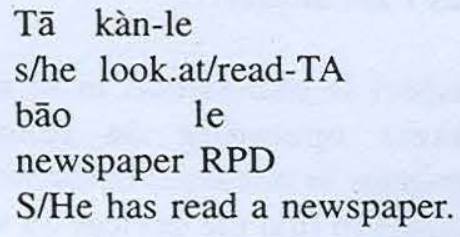

The marker to be discussed in this section is the one suffixed to the verb which is transcribed as -le. The other marker is called sentence-final le (written without hyphen).

If -le refers to the temporal structure of a state of affairs, it only refers to the right (= terminal) time boundary. Consequently, it can only occur with terminative states of affairs or with aterminative state of affairs which get their right boundary from an argument or from a temporal adverbial. In example (5a) there is no temporal boundary. It seems to be for that reason that it is discussed controversially. Most speakers seem to refuse this example because they expect another state of affairs to follow. In (5b) the state of affairs of "living in London" gets its terminal boundary from an adverb and thus becomes accessible to the aspectual interpretation expressed by -le. In (5c) the suffix -le cannot occur because the adverbial expression "since 1950" provides an initial boundary:

(5) Modern Standard Chinese (Li 1992: 157-158):

a. Aterminative verb with no boundary

*/?Tā zài Lúndūn zhù-le. $s /$ he in London live-TA $\mathrm{S} / \mathrm{He}$ lived in London.
b.Aterminative verb with terminal boundary:

Tā zài Lúndūn zhù-le yibèizi. s/he in London live-TA all.one's.life $\mathrm{S} / \mathrm{He}$ lived in London all her/his life.

c. Aterminative verb with initial boundary:

Tā cóng yì jiǔ wǔ líng nián s/he since 1950 year kāishì zhù̀(*-le) zài. Lúndūn begin live-TA in London S/He lives in London since 1950.

As is shown by the following example, -le is interpreted as a past marker with inceptive and stative state of affairs, i.e., states of affairs with the structures [ôö/ CS1 S] and [ö/ S]. In (6a), the use of -le is controversial for the same reason as in (5a). In (6b), however, the state of affairs as a whole gets an initial boundary through the addition of a second verb (shàng. 'lit.: , go up, mount'). Since -le cannot be applied to this boundary, the only interpretation left is that of the past.

(6) Inceptive Resultative Construction and past interpretation:

a. */? Zhāngsān ài-le Mǎlǐ . Zhangsan love-TA Mary Zhangsan loves Mary.

b. Zhāngsān ài-shà-le Mălǐ . Zhangsan love-INCH-TA Mary Zhangsan fell in love with Mary.

The marker -le is called perfective -le in Li \& Thompson's (1981) reference grammar of Chinese. A closer look at this marker reveals that it differs from perfective markers as they are known from prototypical aspect languages in at least the following two ways. Chinese - 
-le is not obligatory, i.e., the speaker is not forced to make a decision between the binary opposition of perfective vs. imperfective - there is always the neutral option of not using any marker at all. The marker -le only refers to the terminal boundary in Modern Standard Chinese, while it refers to any boundaries in languages such as Russian, Bulgarian and Greek. In spite of these differences; it makes sense to call -le a perfective marker inasmuch as parts of its semantics refer to temporal boundaries. However, another component of its meaning must be asso-ciated with past tense. Thus, the application of a selection-theory model based on ASPECT2 in terms of Breu/Sasse interacting with markers whose semantics can be associated with some type of ASPECT1 reveals a combination of tense and aspect functions in one individual marker which has not been discussed in any typology of aspectual systems.

\subsection{Some remarks on Thai}

The present subsection does certainly not aim at presenting an elaborate account of aspect in Thai. It tries to sketch a method of how to describe aspect in Thai in a way which fully allows typological comparison to other aspect systems and at the same time grants as adequate a description of the facts in Thai as possible. At the end of this sub-section, one particular case, i.e., the use of léw with states of affairs denoting actions (ACTI), will be briefly discussed as another instance of the semantics of aspect which seems to have gone unnoticed in the literature (cf. Chinese -le in $\S 3.2$ for another case). The sketch drawn in this subsection continues and further develops the stimulating work on aspect in Thai by
Boonyapatipark (1983), who presented the only thorough study on this topic as far as I am aware.

If aspect is understood in terms of markers operating on temporal boundaries as discussed in section 2 , it is crucial to find the devices by which temporal boundaries are established, then evaluate the way in which potential aspect markers of Thai such as lécw, yùu, yan,kamlan, etc. interact with these boundaries. The first and most basic strategy belongs to the lexicon and concerns semantic verb classes. Although the Breu/Sasse system maximally yields five verb classes as listed in Table 3 above, this does not mean that all of these classes are lexically relevant in every language. There may well be languages whose temporal verb classes turn out to be smaller than five once some of the tests mentioned in Table 2 are applied. Boonyapatipark (1983: 46-62) presents a rather complex classification, which may well turn out to be too complex. In addition to the temporal boundaries which are part of the lexical meaning of verbs, states of affairs can receive temporal boundaries from the following linguistic elements:

- resultative verbs

- phasal verbs/phasal markers

- quantified or definite noun phrases

- adverbs

Resultative construction consist of two verbs, V1 and V2. The second verb (V2), which is called resultative verb, expresses a result of the meaning conveyed by the main verb (V1). If a resultative construction is negated, the negative marker mây 'not' must occur between V1 and V2 and the meaning is that of inability. In quite a number of 
cases, V2 establishes a terminative temporal boundary:

$$
\begin{aligned}
& \text { noon làp [recline - sleep] } \\
& \text { 'sleep, be able to sleep' } \\
& \text { kin Pìm [eat - full] } \\
& \text { 'eat to one's fill' } \\
& \text { moon hěn [look - see] } \\
& \text { 'spot' } \\
& \text { pìt lon [close - move down] } \\
& \text { 'be able to close [something] } \\
& \text { tightly' }
\end{aligned}
$$

Of particular interest are V2 with the meaning of 'finish'. These verbs can be combined with a large number of V1 and may be compared to the terminative Aktionsart.

(8) sèt 'finish (for the time being)' còp 'finish, end'

mòt 'finish (exhaustively)'

Phasality in Thai is expressed by the verbs râəm 'start, begin' and ləิək 'quit, finish, give up' and by the particle tò 'to continue', which immediately follows its verb.

Quantified or definite noun phrases also introduce temporal boundaries. While the indefinite noun phrases in (9a) and (9b) do not introduce any time limit to the state of affairs of 'painting pictures', the definite marker in (9c) or the numeral five in (9d) provide a concrete boundary. As soon as this boundary is reached, a given state of affairs ceases to take place. In the case of definite noun phrases, this stage is reached if the set of items the speaker assumes to be activated in the hearer (cf. Lambrecht 1994) has undergone the action denoted by the predicate. In the case of quantifiers, this stage is reached if the number of items referred to by the numeral is completed.
a. He painted pictures.
b. He painted a picture.
c. He painted the picture.
d. He painted five pictures.

Finally, boundaries can be established by temporal adverbials such as the ones listed under (10):

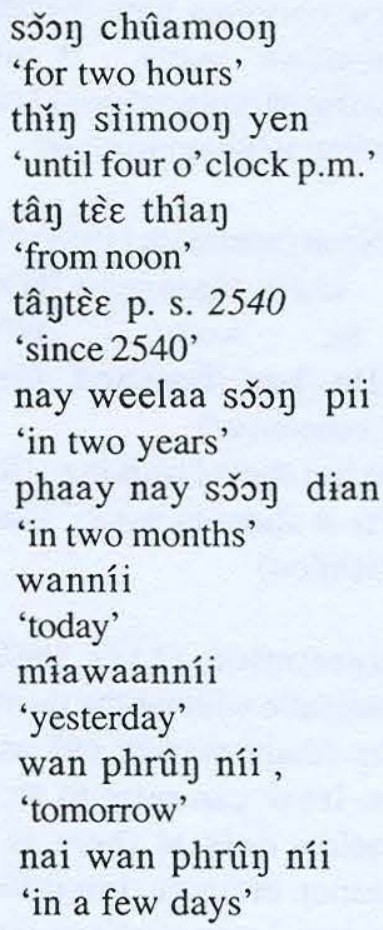

Once the relevant lexical verb classes are established and once the additional devices of introducing temporal boundaries are clear, it is possible to check in what way temporal boundaries interact with potential aspect markers.

As an illustration to the method developed above, I would like to look at the marker l'́zw and its interaction with action verbs (ACTI). The basic function of this marker is described as follows by Boonyapatipark: 
lर́ $\varepsilon \mathrm{W}$ indicates that a crucial amount of some activity has been carried out, a crucial point of a situation has been reached (not necessarily the completion point), i.e. a change to or arrival at a new situation has come about, at the time of reference. (Boonyapatipark 1983: 158 - 159)

If lé $\varepsilon \mathrm{W}$ cooccurs with the action verb tham-naan 'work', it yields the following interpre-tations (11a) to (11c) according to Boonyapatipark :

(11) Boonyapatipark (1983: 157)

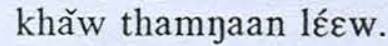
he work PFV

a. 'He has finished his work.' (Completive)

b. 'He has started working.' (Inchoative)

c. 'He is about to work.' (Imminent situation)

Interpretation (11c) seems to be problematic without the overt presence of the future marker cà? as in (12c). Thus, lécw can refer to an imminent situation only if there is an overt indication of future time reference. The other two interpretations in (11a) and (11b) are well established. If needed, they can be disambiguated by using either the verb sèt 'finish' (12a) for the completive function or the verb 'start, begin' (12b) for the inchoative function:

(12) Boonyapatipark (1983: 157)

a. khăw thamjaan sèt lécw $\mathrm{He}$ work finish PFV He has finished his work.'

b. khăw râəm thamıaan lécw. he start work PFV He has started working.

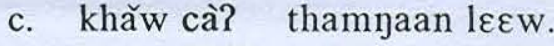
he FUT work PFV $\mathrm{He}$ is about to work.

From the above examples (11a) and (11b) it looks as if léعw can refer to both temporal boundaries with action verbs. If there is no additional marker for disambiguation, context decides whether the boundary applies to the initial or the terminal boundary. If this analysis is true, lé $\mathrm{\varepsilon w}$ is a remarkable aspect marker, because it does not refer to the boundary structures as a whole, it only selects one boundary on which it operates. In languages such as Modern Greek, the perfective aspect marker highlights both boundaries at the same time with action verbs (ACT). I know of no other language in which the aspect marker has a similar semantics.

\section{Conclusion}

If aspect is defined in terms of markers which interact with temporal boundaries East and mainland Southeast Asian languages have markers whose semantics can be compared to aspect markers in aspectual languages such as Greek and others even though these markers are not integrated into an obligatory binary system of perfective vs. imperfective. Interestingly enough, the semantics of these markers deviate from the semantics of European markers in the way in which they interact with temporal boundaries. A more systematic and thorough application of the method for analyzing aspectual functions in East and mainland Southeast Asian languages as suggested in subsection 3.3 may not only reveal the aspectual potential of markers such as lécw, yùu, yan, kamlan, etc. in Thai, it can also show where the aspectual meaning of such markers may significantly deviate 
from the semantics of aspectual markers in European languages.

\section{List of abbreviations in the interlinear glossary of the example sentences}

$\begin{array}{ll}\text { 1,2,3 } & \text { 1st, 2nd, 3rd person } \\ \text { IMP } & \text { Imperfective } \\ \text { INCH } & \text { Inchoative } \\ \text { PASS } & \text { Passive } \\ \text { PFV } & \text { Perfective } \\ \text { PL } & \text { Plural } \\ \text { SG } & \text { Singular } \\ \text { RPD } & \text { Reference to a } \\ & \text { preconstructed } \\ & \text { domain } \\ \text { TA } & \text { Tense-aspect marker } \\ & \text { (Chinese -le) }\end{array}$

\section{References}

Bickel, Balthasar. 1997. Aspectual scope and the difference between logical and semantic representation. Lingua 102 , $115-131$.

Binnick, Robert I. 1991. Time and the Verb. New York/Oxford: Oxford University Press.

Bisang, Walter. 1996. Areal typology and grammaticalization: Processes of grammaticalization based on nouns and verbs in East and mainland South East Asian languages. Studies in Language, 20 (519-597)

Bisang, Walter. 2001. Areality, grammaticalization and language typology. On the explanatory power of functional criteria and the status of Universal Grammar. In: Aspects of Typology and Universals, ed. by Walter Bisang. ed. Berlin: Akademie-Verlag. (175-223)

Bisang, Walter. forth. Grammaticalization without coevolution of form and meaning as an areal phenomenon in East and mainland Southeast Asia the case of tense-aspect-mood (TAM). In: What makes grammati-calization- a look from its components and its fringes, ed. by Walter Bisang \& Björn Wiemer. Berlin: Mouton de Gruyter.

Breu, Walter. 1985. Handlungsgrenzen als Grundlage der Verbklassifikation. In: Slavistische Linguistik 1984, ed. by Werner Lehfeldt, pp. 9-34 München: Sagner.

Breu, Walter. 2000. Zur Position des Slavischen in einer Typologie des Verbalaspekts (Form, Funktion, Ebenenhierarchie und lexikalische Interaktion). In: Probleme der Interaktion von Lexik und Aspekt (ILA), ed. by Walter Breu, pp. $21-54$. Tübingen: Niemeyer.

Boonyapatipark, Tasanalai. 1983. A Study of Aspect in Thai. Unpublished Ph.D. diss. University of London.

Comrie, Bernard. 1976. Aspect. Cam-bridge: Cambridge University Press.

Bybee, Joan L. 1997. Semantic aspects of morphological typology, In: Essays on language function and language type, ed. by Bybee, Joan, Haiman, John \& Thompson, Sandra A, pp. 25 - 37. Amsterdam \& Philadelphia: Benjamins.

Dahl, Östen. 1985. Tense and aspect systems. Oxford: Blackwell.

Dowty, David. 1979. Word meaning and Montague Grammar. Dordrecht: Riedel.

Koschmieder, Erwin. 1928/1929. Studien zum slavischen Verbalaspekt. In: Zeitschrift für vergleichende Sprachforschung 55, 208-304; 56, 78 $-105$.

Koschmieder, Erwin. 1934. Nauka o aspektach czasownika polskiego $w$ zarysie. Próba syntezy. Wilno.

Lambrecht, Knud. 1994. Information structure and sentence form. Cambridge: Cambridge University Press.

Lehmann, Christian. 1995. Thoughts on grammaticalization. München: LINCOM.

Li, Charles N. and Sandra A. Thompson. 1981. Mandarin Chinese (a functional reference grammar). Berkeley, Los Angeles and London: University of California Press. 
Li, Chor-Shing. 1992. Beiträge zur kontrastiven Anthropologie. Das Aspektsystem im Modernen Chinesisch. Bern etc.: Lang. Maslov, Ju. S. 1962. Voprosy glagol'nogo vida $v$ sovremennom zarubez\&nom jazykoznanii, In: Voprosy glagol'nogo vida. Sbornik, ed. by Ju. S. Maslov, pp. 7 - 32. Moskau: Izd. Inostrannoj literatury.

Pollak, W. 1988. Studien zum Verbal-aspekt: Mit besonderer Berücksichtigung des Französischen. Frankfurt am Main: Peter Lang. (1st edition in 1960).

Sasse, Hans-Jürgen. 1991. Aspekttheorie, In: Aspektsysteme, ed. by Hans- Jürgen Sasse, pp. 1-35. (In-stitut für Sprachwissenschaft, Uni-versität zu Köln, Arbeitspapier Nr. 14 [Neue Folge]). Köln: Uni-versität Köln, Institut für Sprach-wissenschaft.

Sasse, Hans-Jürgen. 2002. Recent activity in the theory of aspect: accomplishments, achievements, or just nonprogressive state?. Linguistic Typology 6, 199-271.

Van Valin, Robert D. \& LaPolla, Randy. 1997. Syntax. Structure, meaning and function. Cambridge: Cambridge University Press.

Vendler, Zeno. 1967. Verbs and times, in: Linguistics in Philosophy, 97-121. 